\title{
Resposta da soja ao gesso agrícola em plantio direto no Paraguai ${ }^{1}$
}

\author{
Diego Augusto Fatecha Fois ${ }^{2 *}$, Maria do Carmo Lana ${ }^{2}$, Jimmy Walter Rasche Alvarez, \\ Jucenei Frandoloso ${ }^{2}$, Laura Raquel Quiñonez Vera ${ }^{3}$, Tales Tiecher ${ }^{4}$ \\ 10.1590/0034-737X201865050010
}

\begin{abstract}
RESUMO
A aplicação de gesso em áreas sob plantio direto pode influenciar as características químicas do perfil do solo e aumentar produtividade de soja. Esse trabalho foi realizado com objetivo de avaliar efeito da gessagem na produtividade da soja num Argissolo e Latossolo no Paraguai. O experimento foi realizado nos municípios de Minga Porá e Itakyry, usando delineamento de blocos ao acaso, com seis doses de gesso agrícola $\left(0,100,200,400,800\right.$ e $\left.1600 \mathrm{~kg} \mathrm{ha}^{1}\right)$ e cinco repetições. Aplicou-se gesso em superfície em setembro de 2014 e foram avaliadas duas safras de soja (2014/2015 e 2015/ 2016). Para cada safra foram coletadas amostras de tecido foliar e grãos para determinação dos teores de $\mathrm{P}, \mathrm{K}, \mathrm{Ca}, \mathrm{Mg} \mathrm{e}$ S. Foi avaliada a massa de mil grãos, número de vagens por planta, número de sementes por planta, número de grãos por vagens e rendimento de grãos. Amostras de solo foram coletadas em ambos locais das camadas de 010,1020 e $2040 \mathrm{~cm}$, para determinação de teores de S, K, Ca e Mg disponíveis, saturação por bases e saturação por Al. Os componentes de rendimento e a produtividade da soja não foram influenciados pela aplicação de gesso. Os teores de $\mathrm{Ca}, \mathrm{Mg}, \mathrm{S}, \mathrm{Pe} \mathrm{K}$ no grão e também no tecido foliar da soja não foram afetados pela aplicação das doses de gesso em nenhum local e ano agrícola avaliado. Não houve relação entre a produtividade da soja em todos os cultivos avaliados com o teor de $\mathrm{S}$ e K disponível, Ca e Mg trocável, saturação por bases e saturação por alumínio no solo da camada 010,1020 e $2040 \mathrm{~cm}$.
\end{abstract}

Palavras-chave: enxofre; gessagem; Glycine max; produtividade.

\begin{abstract}
Response of soybean to gypsum in no-till system in Paraguay

The application of gypsum in areas under no-till system can influence the chemical properties of the soil profile and increase soybean productivity. This work was conducted to evaluate the effect of gypsum on soybean productivity in an Argisol and Latosol in Paraguay. The experiment was carried out in the municipalities of Minga Porá and Itakyry, using a randomized block design with six treatments $\left(0,100,200,400,800\right.$, and $1600 \mathrm{~kg}$ ha ${ }^{1}$ of gypsum) and five replications. Gypsum was applied to the surface in September 2014, and two soybean crops (2014/2015 and 2015/2016) were evaluated. Samples of leaf tissue and grains were collected for determination of $\mathrm{P}, \mathrm{K}, \mathrm{Ca}, \mathrm{Mg}$, and $\mathrm{S}$ contents. The mass of 1000 grains, number of pods per plant, number of seeds per plant, number of grains per pods, and grain yield were evaluated. Soil samples were collected in both locations from layers of 0-10, 10-20, and 20-40 cm for determination of $\mathrm{S}, \mathrm{K}, \mathrm{Ca}$, and $\mathrm{Mg}$ available contents, base saturation, and $\mathrm{Al}$ saturation. The components of yield and productivity of soybean were not influenced by gypsum. The contents of $\mathrm{Ca}, \mathrm{Mg}, \mathrm{S}, \mathrm{P}$, and $\mathrm{K}$ in the soybean grain and in leaf tissue were not affected by gypsum doses in any of the locations and crop year evaluated. There was no relationship between soybean yield in all evaluated crops with the available $\mathrm{S}$ and $\mathrm{K}$ content, Ca and exchangeable $\mathrm{Mg}$, base saturation, and aluminum saturation in the soil of the 0-10, 10-20 and 20-40 cm layers
\end{abstract}

Keywords: sulfur; gypsum; Glycine max; productivity.

\footnotetext{
Submetido em 07/08/2009 e aprovado em 20/08/2018.

${ }^{1}$ Este trabalho é parte da tese de doutorado do primeiro autor.

2 Universidade Estadual do Oeste de Paraná, Seção Fertilidade e Nutrição de Plantas, Marechal Candido Rondon, Paraná, Brasil. fatechadiego@ hotmail.com; mariac.lana@ hotmail.com; juceneiff@hotmail.com

${ }^{3}$ Universidad Nacional de Asunción, Facultad de Ciencias Agrarias, San Lorenzo, Paraguay. jwrasche@yahoo.com.ar; lauryqv@gmail.com

${ }^{4}$ Universidade Federal de Rio Grande do Sul, Faculdade de Agronomia, Departamento de Solos, Porto Alegre, Rio grande do Sul, Brasil. tales.tiecher@ufrgs.br

*Autor para correspondência: fatechadiego@hotmail.com
}

Rev. Ceres, Viçosa, v. 65, n.5, p. 450-462, set/out, 2018 


\section{INTRODUÇÃO}

A soja (Glycine max L. Merrill) é a principal cultura agrícola no Paraguai. Atualmente, é cultivada em grande parte do território da Região Oriental, representando $80 \%$ da área cultivada com grãos, com previsão de quase 10 milhões de toneladas produzidas em 2017. Os solos da Região Oriental apresentam níveis médio a baixo de fertilidade com predomínio de solos com teores de enxofre (S) disponível inferiores a $10 \mathrm{mg} \mathrm{dm}^{3}$ no solo na camada 010 cm (Hahn \& Fioretto, 2017).

O S possui função estrutural no metabolismo das plantas, atuando na formação de várias proteínas vegetais e enzimas, na formação da clorofila e promoção da nodulação do sistema radicular. A soja necessita do nutriente para obter altas produtividades, com requerimentos de 40 a 50 $\mathrm{kg} \mathrm{ha}{ }^{1}$ de $\mathrm{S}$ e exportação média de 4 a $5 \mathrm{~kg}$ por $\mathrm{Mg}^{1}$ de grão produzido (Ferreira et al., 2007). No entanto, são escassos os relatos de respostas da cultura à aplicação de $\mathrm{S}$ (Tiecher et al., 2012). Contudo, com o aumento da produtividade das novas cultivares e o uso frequente de fertilizantes concentrados sem $\mathrm{S}$ em sua composição, e a expansão da agricultura à áreas de solos arenosos e com baixo teor de MO, pode ocorrer, sob certas condições, limitação na produtividade devido à deficiência de $\mathrm{S}$ (Crusciol et al., 2014).

Nas áreas cultivadas sob plantio direto (PD) no Paraguai, os corretivos de acidez são normalmente aplicados na superfície do solo, corrigindo facilmente a acidez do solo nessa camada, mas com limitado efeito na redução do alumínio trocável ( $\mathrm{Al}^{3+}$ tóxico) e no incremento de cálcio $\left(\mathrm{Ca}^{2+}\right)$ em subsuperfície (Bortoluzzi et al., 2014). A ocorrência de altos níveis de acidez em subsuperfície pode causar restrição ao crescimento radicular, reduzindo a absorção de água, nutrientes e da produtividade das culturas (Zandoná et al., 2015).

Nesse cenário, a aplicação de gesso agrícola, um subproduto da indústria produtora dos fertilizantes fosfatados, tem sido uma alternativa interessante visando melhorar tanto a disponibilidade de nutrientes, quanto problemas de toxidez de $\mathrm{Al}$ em subsuperfície. $\mathrm{O}$ gesso é uma excelente fonte de $\mathrm{Ca}(20 \%)$ e S (15-18\%), além de contribuir com pequenas concentrações de fósforo (P) $(0,5-0,8 \%)$. Além do seu potencial fertilizante como fonte de macronutrientes, por ser um sal com alta solubilidade, o gesso é comumente comercializado como um condicionador do solo, pois aumenta rapidamente as concentrações de $\mathrm{Ca}^{2+}$ e sulfato $\left(\mathrm{SO}_{4}{ }^{2-}\right.$ ) em subsuperfície (Neis et al., 2010).

O aumento dessas concentrações pode favorecer o crescimento radicular em profundidade tanto pelo fornecimento dos nutrientes $\mathrm{Ca}$ e $\mathrm{S}$, como pela capacidade de diminuir a atividade do $\mathrm{Al}^{3+}$ do solo em subsuperfície e, consequentemente, aliviar sua toxidez às plantas, e tam- bém pela promoção do carreamento de outras bases, como $\mathrm{Mg}^{2+} \mathrm{e} \mathrm{K}^{+}$, para camadas de solo mais profundas (Saldanha et al., 2007). Por outro lado, a recomendação e utilização generalizada desse condicionador, aumenta desnecessariamente o custo de produção e pode causar efeitos indesejados, como a excessiva lixiviação de bases trocáveis $\left(\mathrm{Mg}^{2+}\right.$ e K $\mathrm{K}^{+}$, causando deficiências nutricionais e redução da produtividade de soja (Fontoura et al., 2012).

Ainda não existe uma recomendação precisa de critérios de tomada de decisão e de doses a serem utilizadas na aplicação de gesso na cultura de soja (Caires et al., 2011b). Apesar dos benefícios nas propriedades químicas do solo promovidas pela aplicação de gesso, vários estudos realizados em solos do estado de Paraná, não têm observado incremento na produtividade de soja com aplicação superficial de gesso agrícola em áreas sob plantio direto (Soratto et al., 2010; Rampin et al., 2011; Neis et al., 2010; Caires et al., 2011b).

Existem estudos que observaram aumento nas concentrações de $\mathrm{Ca}, \mathrm{Mg}$, K e S foliar na soja com aplicação de gesso (Rampin et al. 2011; Moda et al., 2013), porém sem influenciar a produtividade de grãos. Outros estudos destacam que a resposta da soja é observada principalmente em safras com déficit hídrico, devido ao maior crescimento radicular em profundidade nos tratamentos com gesso agrícola (Alcântara et al., 2014). Por fim, alguns estudos apontam, ainda, que pode haver redução da produtividade de soja com aplicação de doses muito elevadas de gesso agrícola por indução de deficiência de $\mathrm{Mg}$ (Pauletti et al., 2014). Como pode ser visto, na literatura brasileira existem vários estudos envolvendo a resposta da soja à gessagem. Contudo, estudos dessa natureza ainda são escassos no Paraguai.

O objetivo desse trabalho foi avaliar os efeitos da gessagem na cultura da soja em plantio direto em um Argissolo e um Latossolo do Departamento do Alto Paraná, Paraguai.

\section{MATERIAL E MÉTODOS}

\section{Descrição dos locais de estudo}

O experimento foi realizado nos anos agrícolas de 2014/ 2015 e 2015/2016, nos municípios de Itakyry e Minga Porá, situadas no Departamento do Alto Paraná, Região Oriental do Paraguai. As áreas experimentais foram instaladas em propriedades rurais de agricultores locais, com rotações e/ou sucessões de culturas de soja/milho no verão e trigo ou planta de cobertura no inverno, em sistema de plantio direto há seis e onze anos, respectivamente.

Os solos foram classificados segundo López et al. (1995) como Rhodic Paleudult (Itakyry) com textura arenosa e fertilidade média e Rhodic Kandiudox (Minga Porá) com textura muito argilosa e de fertilidade baixa, segundo 
o sistema Soil Taxonomy (Soil Survey Division Staff, 1993). No Sistema Brasileiro de Classificação de Solos (Embrapa, 2013) os solos classificam-se como Argissolo VermelhoAmarelo Distrófico (PVad) e Latossolo Vermelho Distróférrico $(\mathrm{LVd})$, respectivamente.

A caracterização físico-química do solo antes da calagem e três meses antes da instalação dos experimentos é apresentada na Tabela 1. O solo de Itakyry e Minga Porá na camada $010 \mathrm{~cm}$ apresentaram saturação por bases médio (62\%) e baixa (41\%), e saturação por Al baixa (2\%) e alta (20\%), respectivamente. Ambos os locais apresentavam baixa saturação por bases $(<31 \%)$ e alta saturação por $\mathrm{Al}(>20 \%$ ) abaixo de $10 \mathrm{~cm}$ de profundidade. Os teores de $\mathrm{S}$ nas áreas experimentais estavam próximos ao ideal $\left(9,2 \mathrm{e} 7,1 \mathrm{mg} \mathrm{dm}^{3}\right)$, os teores de $\mathrm{Ca}$ abaixo do teor adequado $\left(2,5\right.$ e 2,6 $\left.\mathrm{cmol}_{\mathrm{c}} \mathrm{dm}^{3}\right)$ e os teores de $\mathrm{Mg}$ acima do teor crítico $\left(1,7\right.$ e $\left.1,3 \mathrm{cmol}_{\mathrm{c}} \mathrm{dm}^{3}\right)$ na profundidade de $010, \mathrm{~cm}$ respectivamente (CQFS/RS-SC, 2016).

As precipitações médias nos dois locais de estudo a $31 \mathrm{~km}$ de distância, no primeiro e segundo ano agrícola foram de 527 e $881 \mathrm{~mm}$, respectivamente, com chuvas bem distribuídas ao longo do período de cultivo da soja (Figura 1), atendendo às necessidades hídricas para a produção máxima, que varia entre $450 \mathrm{a} 800 \mathrm{~mm}$ por safra (Embrapa, 2003).

Em Minga Porá, três meses antes da instalação do experimento aplicou-se calcário dolomítico com $90 \%$ de PRNT. A aplicação foi realizada à lanço na superfície do solo, na dose de $2.500 \mathrm{~kg} \mathrm{ha}^{1}$, a qual foi calculada para elevar a saturação por bases a $70 \%$ na camada de $0-20 \mathrm{~cm}$.

\section{Delineamento e desenho experimental e manejo da cultura da soja}

Em Itakyry e Minga Porá foram avaliadas duas safras de soja (2014/2015 e 2015/2016), utilizando delineamento de blocos ao acaso, com seis doses de gesso agrícola de 0 , $100,200,400,800$ e $1.600 \mathrm{~kg} \mathrm{ha}^{1}$ e cinco repetições. As doses foram definidas visando dois objetivos diferentes. A menor dose foi definida visando o fornecimento de $\mathrm{S}$ e a maior dose visando à mitigação da atividade do $\mathrm{Al}^{3+} \mathrm{em}$ subsuperfície. Segundo a recomendação de Sousa et al. (2005) e do NEPAR-SBCS (2017), calculou-se a dose de gesso a ser aplicada de acordo a classificação textural do solo na camada de $20-40 \mathrm{~cm}$, que correspondeu a $1200 \mathrm{e}$ $2200 \mathrm{~kg} \mathrm{ha}{ }^{1}$ em Itakyry e Minga Porá, respectivamente. Doses mais elevadas não foram testadas, pois estudos indicam que podem causar a lixiviação e deficiência induzida de $\mathrm{Ke} \mathrm{Mg}$ (Fontoura et al., 2012). As unidades experimentais mediam $8 \times 8 \mathrm{~m}\left(64,0 \mathrm{~m}^{2}\right)$ totalizando $1.920 \mathrm{~m}^{2}$ de área total. A aplicação do gesso em superfície em dose única foi realizada em setembro de 2014 sobre palhada de aveia preta em Itakyry e trigo em Minga Porá.

Em Itakyry, a cultivar de soja transgênica SYNGENTA 9070 foi semeada nos dias 4 de outubro de 2014 (safra 2014/2015) e 24 de setembro de 2015 (safra 2015/2016). Em Minga Porá a cultivar de soja INTACTA 6410 foi semeada nos dias 1 de outubro de 2014 (safra 2014/2015) e 30 de setembro de 2015 (safra 2015/2016). O espaçamento entrelinhas utilizado foi de $45 \mathrm{~cm}$, com 12 sementes por metro linear, numa densidade de 266.664 sementes ha ${ }^{1}$. Aplicaram-se, em cada safra, $200 \mathrm{~kg} \mathrm{ha}^{1}$ de fertilizante NPK 4-30-

Tabela 1: Caracterização físico-química do solo antes da aplicação do calcário das camadas 0-10, 10-20 e 20-40 cm

\begin{tabular}{|c|c|c|c|c|c|c|c|}
\hline \multirow{2}{*}{ Característica } & & \multicolumn{3}{|c|}{ Unidade Local Itakyry (PVad) } & \multicolumn{3}{|c|}{ Local Minga Porá (LVd) } \\
\hline & & $010 \mathrm{~cm}$ & $1020 \mathrm{~cm}$ & $2040 \mathrm{~cm}$ & $010 \mathrm{~cm}$ & $1020 \mathrm{~cm}$ & $2040 \mathrm{~cm}$ \\
\hline $\mathrm{pH}^{(1)}$ & & 5,7 & 4,8 & 4,4 & 4,7 & 4,2 & 4,1 \\
\hline $\mathrm{Al}^{(2)}$ & $\mathrm{cmol}_{\mathrm{c}} \mathrm{dm}^{3}$ & 0,1 & 0,4 & 0,6 & 1,2 & 1,3 & 1,4 \\
\hline $\mathrm{H}+\mathrm{Al}^{(3)}$ & $\mathrm{cmol}_{\mathrm{c}} \mathrm{dm}^{3}$ & 2,7 & 3,7 & 4,2 & 6,7 & 9,7 & 9,7 \\
\hline $\mathrm{Ca}^{(2)}$ & $\mathrm{cmol}_{\mathrm{c}}^{\mathrm{c}} \mathrm{dm}^{3}$ & 2,5 & 1,1 & 0,9 & 2,6 & 2,3 & 2,1 \\
\hline $\operatorname{Mg}^{(2)}$ & $\mathrm{cmol}_{\mathrm{c}} \mathrm{dm}^{3}$ & 1,7 & 0,4 & 0,3 & 1,3 & 0,9 & 0,7 \\
\hline $\mathrm{K}^{(4)}$ & $\mathrm{cmol}_{\mathrm{c}} \mathrm{dm}^{3}$ & 0,30 & 0,12 & 0,09 & 0,70 & 0,61 & 0,50 \\
\hline SB & $\mathrm{cmol}_{\mathrm{c}} \mathrm{dm}^{3}$ & 4,6 & 1,6 & 1,4 & 4,7 & 3,9 & 3,4 \\
\hline CTC $\mathrm{pH} 7,0$ & $\mathrm{cmol}_{\mathrm{c}} \mathrm{dm}^{3}$ & 7,3 & 5,3 & 5,6 & 11,4 & 13,6 & 13,1 \\
\hline $\mathrm{V}$ & $\%$ & 63 & 31 & 24 & 41 & 29 & 26 \\
\hline $\mathrm{m}$ & $\%$ & 2 & 20 & 32 & 21 & 26 & 30 \\
\hline $\operatorname{MO}\left({ }^{6}\right)$ & $\mathrm{g} \mathrm{kg}^{3}$ & 15 & 10 & 7 & 42 & 35 & 20 \\
\hline $\mathrm{P}^{(4)}$ & $\mathrm{mg} \mathrm{dm}{ }^{3}$ & 28,0 & 25,5 & 7,23 & 26,3 & 12,4 & 5,2 \\
\hline$S^{(5)}$ & $\mathrm{mg} \mathrm{dm}^{3}$ & 9,2 & 10,4 & 12,5 & 7,1 & 7,6 & 8,1 \\
\hline$\overline{\text { Areia }^{(7)}}$ & $\mathrm{g} \mathrm{kg}^{3}$ & 790 & 860 & 900 & 430 & 420 & 380 \\
\hline Silte $^{(7)}$ & $\mathrm{g} \mathrm{kg}^{3}$ & 80 & 40 & 20 & 140 & 130 & 160 \\
\hline $\operatorname{Argila}^{(7)}$ & $\mathrm{g} \mathrm{kg}^{3}$ & 130 & 90 & 80 & 430 & 450 & 460 \\
\hline
\end{tabular}

(1) $\mathrm{pH}$ em $\mathrm{CaCl}^{2}$, relação 1:2,5. ${ }^{(2)}$ Extrator $\mathrm{KCl} 1 \mathrm{~mol} \mathrm{~L}^{1} .{ }^{\left({ }^{3}\right.}$ Extrator acetato de cálcio 0,5 mol L ${ }^{1} \mathrm{pH}$ 7,0. ${ }^{(4)}$ Extrator Mehlich-1. ${ }^{(5)}$ Extrator $\mathrm{Ca}\left(\mathrm{H}_{2} \mathrm{PO}_{4}\right)_{2} 500 \mathrm{mg} \mathrm{L}^{1}$ de $\mathrm{P}$ em HOAc $\left.2 \mathrm{~mol} \mathrm{~L}^{1} .{ }^{6}\right)$ Walkley-Black ( $\left.{ }^{7}\right)$ Método do densímetro (Lana et al., 2016). 
10 na semeadura da soja, como adubação de reposição. Os teores de $\mathrm{P}$ e $\mathrm{K}$ em ambos locais estavam acima dos níveis críticos.

Antes da semeadura da cultura da soja em todas as safras e locais estudados, foram necessários tratamentos de sementes com tiametoxan $\left(40 \mathrm{~g}\right.$ ia ha $\left.{ }^{1}\right)+$ clorotalonil $(3,5$ $\mathrm{L}$ ha ${ }^{1}$ ) para controlar ataque de insetos (Elasmopalpus lignosellus, Diabrotica speciosa) e fungos das sementes (Phomopsis spp. Cercospora sojina, Fusarium spp.) e protegê-las contra fungos do solo (Alternaria solani, Colletotrichum spp.). Durante o ciclo, para controle de ervas invasoras (Bidens pilosa, Commelina ereta, Cenchrus echinatus) das áreas foram realizadas aplicações de glyfosate $\left(1,5 \mathrm{~L} \mathrm{ha}^{1}\right)$ e bentazon $\left(1,2 \mathrm{~L} \mathrm{ha}^{1}\right)$. Contra o ataque de lagartas (Anticarsia gemmatalis, Pseudoplusia includens) e percevejos (Nezara viridula, Euschistus heros) foram aplicadas imidacloprido $\left(75 \mathrm{~g}\right.$ ia ha $\left.{ }^{1}\right)$ tiametoxan $\left(40 \mathrm{~g}_{\text {ia ha }}{ }^{1}\right.$ ). Para o manejo de doenças (ferrugem, mancha parda da folha, crestamento foliar de cercospora, antracnose) foram realizadas aplicações preventivas de fungicidas com os produtos tebuconaloze (100 $\mathrm{g}$ ia ha $\left.{ }^{1}\right)$, carbendazim $\left(0,5 \mathrm{~kg} \mathrm{ha}^{1}\right)$ epiconazole $\left(0,5 \mathrm{~kg} \mathrm{ha}^{1}\right)$.

\section{Avaliações}

A produtividade da soja foi estimada em uma área de $8,1 \mathrm{~m}^{2}$ por parcela. Foram determinados componentes de produtividade de grãos da cultura de soja como número de grãos por planta, número de vagens por planta, número
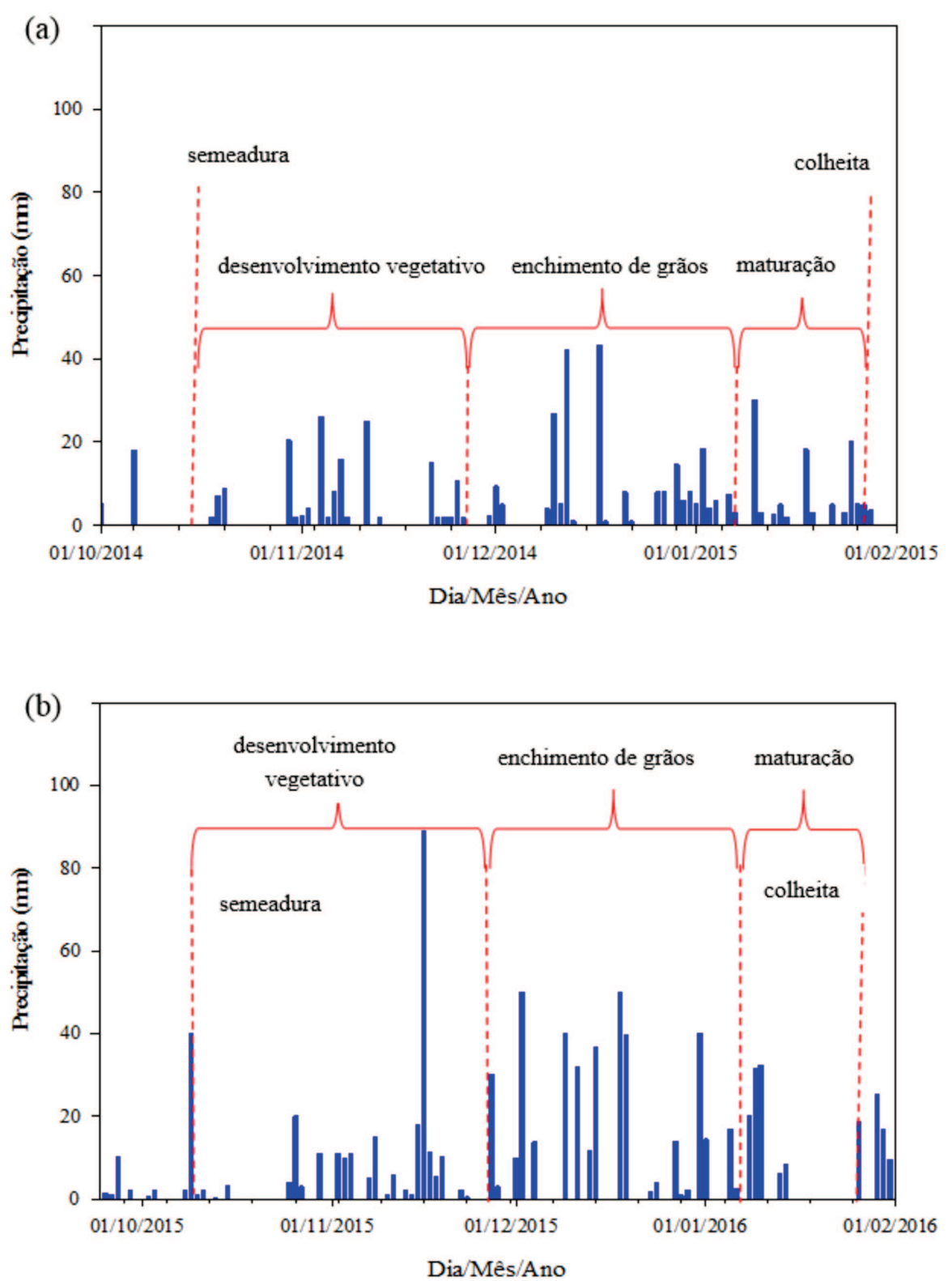

Fonte: Fecoprod, 2017.

Figura 1: Precipitação pluviométrica mensal ocorrida nos períodos de outubro de 2014 a fevereiro de 2015 (a) e outubro de 2015 a fevereiro de 2016 (b), durante a condução do experimento a campo nos locais de Itakyry e Minga Porá. 
de grãos por vagens, massa de mil grãos e rendimento de grãos. No momento da colheita da cultura foram coletadas amostras de $100 \mathrm{~g}$ de grãos de soja para determinação de teores de Ca, Mg, S, P e K (Lana et al., 2016).

Na safra de 2015/16, no início do florescimento foram feitas amostragem de folhas, coletando-se a terceira folha a partir do ápice das plantas, num total de 20 subamostras por parcela, para análise química dos teores de $\mathrm{Ca}, \mathrm{Mg}, \mathrm{S}$, P e K (Lana et. al., 2016). Após secagem e moagem, amostras de grãos e folhas foram digeridas em meio ácido utilizando a mistura nítrico perclórica na proporção 3:1. Em seguida determinaram-se os teores de $\mathrm{Ca}$ e $\mathrm{Mg}$ por espectrofotometria de absorção atômica e K por emissão de chamas. Os teores de $\mathrm{S}$ e $\mathrm{P}$ nos extratos foram determinados por turbidimetria e espectrofotometria UV-vis, respectivamente (Lana et al., 2016).

As amostragens foram realizadas oito e vinte meses após a aplicação de gesso, utilizando pá de corte com 3 subamostras por parcela para compor uma amostra composta das camadas de 010,1020 e $2040 \mathrm{~cm}$. Após secagem a $50^{\circ} \mathrm{C}$ e peneiramento a $2 \mathrm{~mm}$, foram determinados o teor de $\mathrm{S}$ extraído com fosfato de cálcio $\left(500 \mathrm{mg} \mathrm{L}^{1} \mathrm{de} \mathrm{P}\right.$ em ácido acético (HOAc 2 mol L ${ }^{1}$ ) com posterior determinação pelo método turbidimétrico. Os teores de $\mathrm{Ca}, \mathrm{Mg}$ e $\mathrm{Al}$ trocáveis foram extraídos com $\mathrm{KCl} 1,0 \mathrm{~mol} \mathrm{~L}^{1}$. O teor de $\mathrm{K}$ disponível extraído por Mehlich 1, e determinado por fotômetro de chama. O Al trocável foi determinado por titulação com solução de $\mathrm{NaOH} 0,015 \mathrm{~mol} \mathrm{~L}^{1}$; Ca e $\mathrm{Mg}$ foram determinados por espectrometria de absorção atô- mica. A acidez potencial $(\mathrm{H}+\mathrm{Al})$ foi estimada por correlação com o valor obtido do pH SMP. A soma de bases (SB) foi calculada somando-se os teores de $\mathrm{Ca}, \mathrm{Mg}$ e K . Posteriormente, foram calculados a saturação por bases (V) com uso da fórmula: $\mathrm{V}(\%)=100 \times \mathrm{SB} / \mathrm{CTC}_{\mathrm{pH}, 0}$ e a saturação por $\mathrm{Al}(\mathrm{m})$ foi obtida pela relação: $\mathrm{m}(\%)=[\mathrm{Al} /(\mathrm{SB}+\mathrm{Al})] \times$ 100 (Lana et al., 2016).

Para esse estudo, foram utilizados os valores críticos de $\mathrm{S}, \mathrm{Ca}, \mathrm{Mg}, \mathrm{K}, \mathrm{V} \%$ e m\% estabelecidos pela CQFS-SC/ RS (2016). O gráfico que descreve a variação de RR (eixo y) em relação aos valores de S, Ca, Mg, K, V\% ou m\% (eixo x) foram definidos considerando-se a média dos pontos obtidos do RR no experimento, que foi de $85 \%$, calculado considerando-se a produtividade máxima obtida no experimento (4402 $\mathrm{kg} \mathrm{ha}^{1}$ ), que permitiu uma melhor distribuição dos pontos, de acordo com Cate \& Nelson (1971).

\section{Análises estatísticas}

Inicialmente submeteram-se os dados à análise de variância para cada local em separado e avaliou-se a razão entre os valores dos quadrados médios dos resíduos dos locais. Como na maioria dos casos a razão foi inferior a 7, de acordo com a recomendação de Pimentel Gomes (2002), optou-se pela análise conjunta dos experimentos. Quando os efeitos foram significativos $(p<0,05)$ pelo teste $\mathrm{F}$, foram ajustadas equações de regressão para as doses de gesso e as diferenças entre os locais de estudo foram comparados pelo teste de Tukey a $p<0,05$, utilizando-se o programa INFOSTAT (Di Renzo et al., 2011).

Tabela 2: Número de vagens por planta (NVP), número grãos por planta (NGP), número de grão por vagens (NGV), massa de mil grãos (MMG) e produtividade de grãos (PG) da soja em função de diferentes doses de gesso, considerando as média dos locais Itakyry e Minga Porá, e anos agrícolas 2014/2015 e 2015/2016

\begin{tabular}{|c|c|c|c|c|c|}
\hline Dose de gesso & \multirow{2}{*}{ NVP } & \multirow{2}{*}{ NGP } & \multirow{2}{*}{ NGV } & \multirow{2}{*}{$\begin{array}{c}\text { MMG } \\
\text { g } \\
\end{array}$} & \multirow{2}{*}{$\begin{array}{c}\text { PG } \\
\text { t ha }^{-1}\end{array}$} \\
\hline $\mathrm{kg} \mathrm{ha}^{-1}$ & & & & & \\
\hline 0 & $67,5^{\mathrm{ns}}$ & $165,3^{\mathrm{ns}}$ & $2,43^{\mathrm{ns}}$ & $140,7^{\mathrm{ns}}$ & $3,80^{\mathrm{ns}}$ \\
\hline 100 & 64,5 & 159,1 & 2,45 & 141,4 & 3,92 \\
\hline 200 & 67,5 & 163,2 & 2,46 & 138,9 & 3,95 \\
\hline 400 & 67,6 & 161,0 & 2,41 & 139,5 & 3,88 \\
\hline 800 & 69,7 & 171,2 & 2,44 & 139,1 & 3,78 \\
\hline 1600 & 65,3 & 160,8 & 2,44 & 141,5 & 4,22 \\
\hline \multicolumn{6}{|l|}{ Local } \\
\hline IT & $78,9 \mathrm{a}$ & $194,5 \mathrm{a}$ & $2,46 \mathrm{a}$ & $132,4 \mathrm{~b}$ & $4,1 \mathrm{a}$ \\
\hline MP & $55,1 \mathrm{~b}$ & $132,3 \mathrm{~b}$ & $2,42 \mathrm{a}$ & $147,9 \mathrm{a}$ & $3,6 \mathrm{~b}$ \\
\hline \multicolumn{6}{|l|}{ Ano agrícola } \\
\hline $2014 / 2015$ & $72,35 \mathrm{a}$ & $169,9 \mathrm{a}$ & $2,35 \mathrm{a}$ & $141,6 \mathrm{a}$ & $3,6 \mathrm{~b}$ \\
\hline $2015 / 2016$ & $61,73 \mathrm{~b}$ & $157,0 \mathrm{~b}$ & $2,53 \mathrm{a}$ & $138,8 \mathrm{~b}$ & $4,1 \mathrm{a}$ \\
\hline \multicolumn{6}{|c|}{ Fator experimental } \\
\hline Local $(\mathrm{L}) \times \mathrm{G}$ & $1,24^{\mathrm{ns}}$ & $0,77^{\mathrm{ns}}$ & $2,16^{\mathrm{ns}}$ & $1,70^{\mathrm{ns}}$ & $1,33^{\mathrm{ns}}$ \\
\hline Ano $($ A $) \times G$ & $0,89^{\mathrm{ns}}$ & $0,54^{\mathrm{ns}}$ & $0,36^{\mathrm{ns}}$ & $0,66^{\mathrm{ns}}$ & $0,94^{\mathrm{ns}}$ \\
\hline $\mathrm{L} \times \mathrm{G} \times \mathrm{A}$ & $2,08^{\mathrm{ns}}$ & $0,96^{\mathrm{ns}}$ & $2,12^{\mathrm{ns}}$ & $1,27^{\mathrm{ns}}$ & $1,53^{\mathrm{ns}}$ \\
\hline
\end{tabular}

*significativo a 5\% de probabilidade pelo teste F; ns = não significativo. As médias seguidas de letras diferentes na coluna diferem entre sí pelo teste $\mathrm{F}$ a $\mathrm{p}<0,05 \%$.

Rev. Ceres, Viçosa, v. 65, n.5, p. 450-462, set/out, 2018 


\section{RESULTADOS E DISCUSSÃO}

\section{Componentes de produtividade de grãos}

Os componentes de produtividade de grãos de soja não foram afetados pela aplicação das doses de 0 a 1600 $\mathrm{kg} \mathrm{ha}{ }^{1}$ de gesso agrícola nos dois locais estudados (Itakyry e Minga Porá) e em todas as safras avaliadas (safras 2014/ 2015, 2015/2016 (Tabela 2). Não foram observadas interações de local $\times$ gesso, ano $\times$ gesso e local $\times$ ano $\times$ gesso nos dois anos.

A falta de resposta da produtividade da soja às doses de gesso evidenciou que os teores de $\mathrm{S}$ nesses solos não eram limitantes. O S nativo do solo proveniente da mineralização da matéria orgânica (MO) e a deposição atmosférica de S (Tiecher et al., 2013), podem ter sido suficientes para suprir as necessidades da cultura em ambos

Tabela 3: Valores médios de teores foliares de $\mathrm{Ca}, \mathrm{Mg}, \mathrm{S}, \mathrm{Pe} \mathrm{K}$ na cultura da soja, em função a diferentes doses de gesso considerando a média dos locais Itakyry e Minga Porá para o ano agrícola 2015/2016

\begin{tabular}{|c|c|c|c|c|c|}
\hline \multirow{2}{*}{ Tratamentos } & $\mathbf{C a}$ & Mg & $\mathbf{S}$ & $\mathbf{P}$ & $\mathbf{K}$ \\
\hline & \multicolumn{5}{|c|}{$\mathrm{g} \mathrm{kg}^{1}$} \\
\hline \multicolumn{6}{|c|}{ Dose de gesso $\left(\mathrm{kg} \mathrm{ha}^{1}\right)$} \\
\hline 0 & $6,0^{\mathrm{ns}}$ & $5,4^{\mathrm{ns}}$ & $2,8^{\mathrm{ns}}$ & $4,4^{\mathrm{ns}}$ & $16,3^{\mathrm{ns}}$ \\
\hline 100 & 7,0 & 5,7 & 2,7 & 4,3 & 16,0 \\
\hline 200 & 6,7 & 5,9 & 3,5 & 4,5 & 16,4 \\
\hline 400 & 6,5 & 5,8 & 2,9 & 4,2 & 15,3 \\
\hline 800 & 6,5 & 5,5 & 3,1 & 4,2 & 16,5 \\
\hline 1600 & 6,8 & 5,1 & 3,8 & 4,3 & 15,6 \\
\hline \multicolumn{6}{|l|}{ Local } \\
\hline IT & $8,0 \mathrm{a}$ & 8,6 a & $4,0 \mathrm{a}$ & $3,4 \mathrm{a}$ & $16,5 \mathrm{~b}$ \\
\hline MP & $4,2 \mathrm{~b}$ & $6,8 \mathrm{~b}$ & $2,9 \mathrm{~b}$ & $3,1 \mathrm{~b}$ & $18,0 \mathrm{a}$ \\
\hline \multicolumn{6}{|c|}{ Fator experimental } \\
\hline Local (L) & $<0,001 *$ & $0,0019 *$ & $0,0318 *$ & $0,0887^{\mathrm{ns}}$ & $0,0019 *$ \\
\hline Gesso (G) & $0,3200^{\mathrm{ns}}$ & $0,6273^{\mathrm{ns}}$ & $0,1013^{\mathrm{ns}}$ & $0,3393^{\mathrm{ns}}$ & $0,6241^{\mathrm{ns}}$ \\
\hline Local $(\mathrm{L}) \times \mathrm{G}$ & $0,1195^{\mathrm{ns}}$ & $0,4382^{\text {ns }}$ & $0,7341^{\mathrm{ns}}$ & $0,6806^{\mathrm{ns}}$ & $0,7776^{\mathrm{ns}}$ \\
\hline
\end{tabular}

*significativo a $5 \%$ de probabilidade pelo teste $\mathrm{F}$; ns = não significativo. As médias seguidas de letras diferentes na coluna diferem entre sí pelo teste F.

Tabela 4: Teores de Ca, Mg, S, P e K nos grãos da cultura da soja, em função de diferentes doses de gesso, considerando média dos locais Itakyry e Minga Porá e a média dos anos agrícolas 2014/2015 e 2015/2016

\begin{tabular}{|c|c|c|c|c|c|}
\hline \multirow{2}{*}{$\frac{\text { Dose de gesso }}{\text { kg ha }^{1}}$} & $\mathbf{C a}$ & Mg & $\mathbf{S}$ & $\mathbf{P}$ & $\mathbf{K}$ \\
\hline & \multicolumn{5}{|c|}{$\mathrm{g} \mathrm{kg}^{1}$} \\
\hline 0 & $4,54^{\mathrm{ns}}$ & $2,66^{\mathrm{ns}}$ & $2,73^{\mathrm{ns}}$ & $5,29^{\mathrm{ns}}$ & $15,34^{\mathrm{ns}}$ \\
\hline 100 & 4,75 & 2,76 & 2,89 & 5,23 & 15,68 \\
\hline 200 & 4,99 & 2,75 & 2,88 & 5,40 & 15,13 \\
\hline 400 & 4,72 & 2,73 & 2,92 & 5,22 & 14,70 \\
\hline 800 & 4,64 & 2,61 & 2,84 & 5,25 & 14,81 \\
\hline 1600 & 5,06 & 2,63 & 2,94 & 5,15 & 15,02 \\
\hline \multicolumn{6}{|l|}{ Local } \\
\hline IT & $4,68 \mathrm{a}$ & $2,69 \mathrm{a}$ & $2,91 \mathrm{a}$ & $4,95 \mathrm{a}$ & $14,21 \mathrm{a}$ \\
\hline MP & $4,19 \mathrm{~b}$ & $2,30 \mathrm{~b}$ & $2,43 \mathrm{~b}$ & $4,77 \mathrm{a}$ & $13,44 \mathrm{~b}$ \\
\hline \multicolumn{6}{|l|}{ Ano agrícola } \\
\hline $2014 / 2015$ & $5,36 \mathrm{a}$ & $2,80 \mathrm{a}$ & $3,27 \mathrm{a}$ & $5,07 \mathrm{a}$ & $16,85 \mathrm{a}$ \\
\hline $2015 / 2016$ & $4,20 \mathrm{~b}$ & $2,59 \mathrm{a}$ & $2,46 \mathrm{~b}$ & $5,25 \mathrm{a}$ & $13,04 \mathrm{~b}$ \\
\hline \multicolumn{6}{|c|}{ Fator experimental } \\
\hline Local $(\mathrm{L}) \times \mathrm{G}$ & $0,6555^{\mathrm{ns}}$ & $0,4494^{\mathrm{ns}}$ & $0,4117^{\mathrm{ns}}$ & $0,8970^{\mathrm{ns}}$ & $0,6117^{\text {ns }}$ \\
\hline Ano $(A) \times G$ & $0,7065^{\mathrm{ns}}$ & $0,5722^{\mathrm{ns}}$ & $0,4917^{\mathrm{ns}}$ & $0,9742^{\text {ns }}$ & $0,3362^{\mathrm{ns}}$ \\
\hline $\mathrm{L} \times \mathrm{G} \times \mathrm{A}$ & $0,7247^{\mathrm{ns}}$ & $0,1244^{\mathrm{ns}}$ & $0,5339^{\text {ns }}$ & $0,8572^{\mathrm{ns}}$ & $0,5933^{\text {ns }}$ \\
\hline
\end{tabular}

*significativo a $5 \%$ de probabilidade pelo teste $\mathrm{F} ; \mathrm{ns}=$ não significativo. As médias seguidas de letras diferentes na coluna diferem entre sí pelo teste $\mathrm{F}$ 
locais. Em solos da região Pampeana de Argentina, Gentiletti \& Gutiérrez (2004) também não observaram resposta de vários cultivares de soja à fertilização com gesso agrícola em solos com altos teores de MO, como observado no experimento de Minga Porá.

Os efeitos da aplicação de gesso neste trabalho são de curto prazo (1 a 2 anos após aplicação de gesso). Muitos autores têm observado efeito residual do gesso, com in- crementos de produtividade na soja após três (Caires et al., 2011a) e cinco anos (Sousa et al., 2005), após a aplicação de gesso devido ao processo de migração gradual de $\mathrm{SO}_{4}{ }^{2}$ e $\mathrm{Ca}^{2+}$ em subsuperfície.

Além disso, a ausência de déficit hídrico (Figura 1) pode ser apontada também como fator que resultou na falta de resposta da soja à aplicação do gesso. A capacidade do gesso de proporcionar maior desenvolvimento

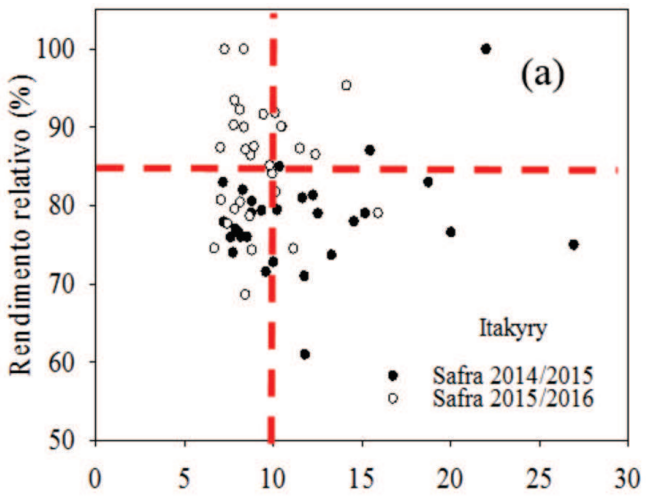

Teor de $\mathrm{S}$ disponível no solo da camada $0-10 \mathrm{~cm}\left(\mathrm{mg} \mathrm{dm}^{-3}\right)$

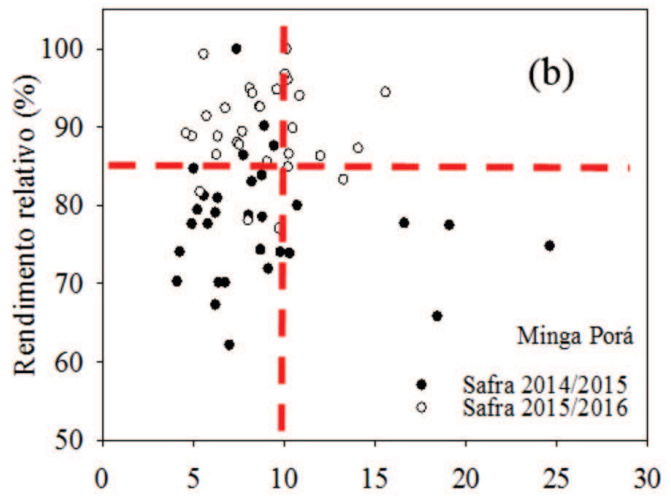

Teor de $\mathrm{S}$ disponível no solo da camada $0-10 \mathrm{~cm}\left(\mathrm{mg} \mathrm{dm}^{-3}\right)$
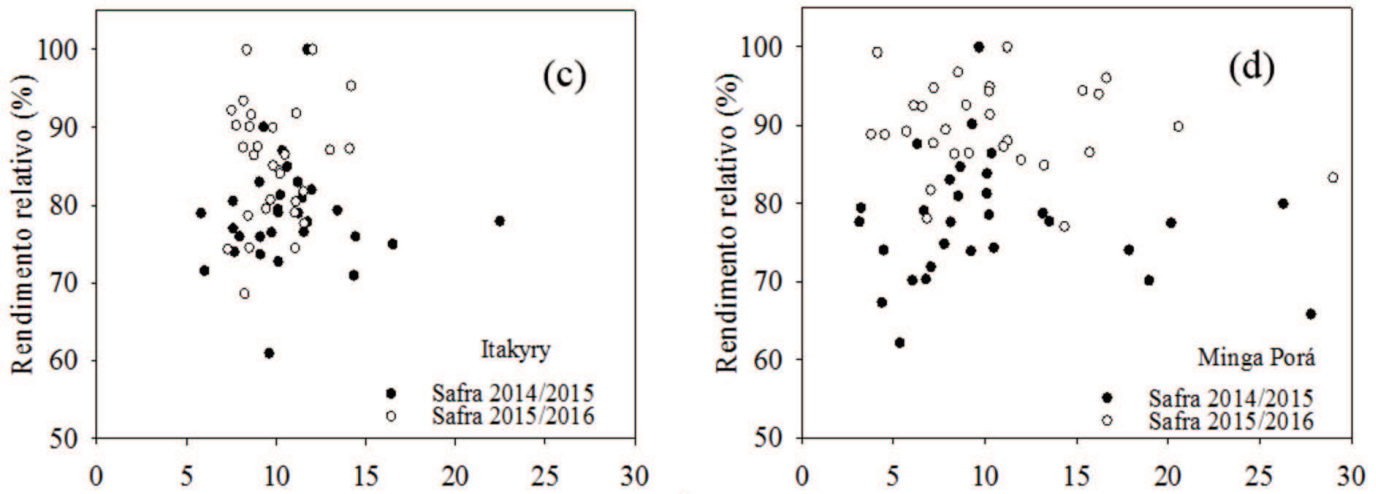

Teor de $\mathrm{S}$ disponivel no solo da camada $10-20 \mathrm{~cm}\left(\mathrm{mg} \mathrm{dm}^{-3}\right)$
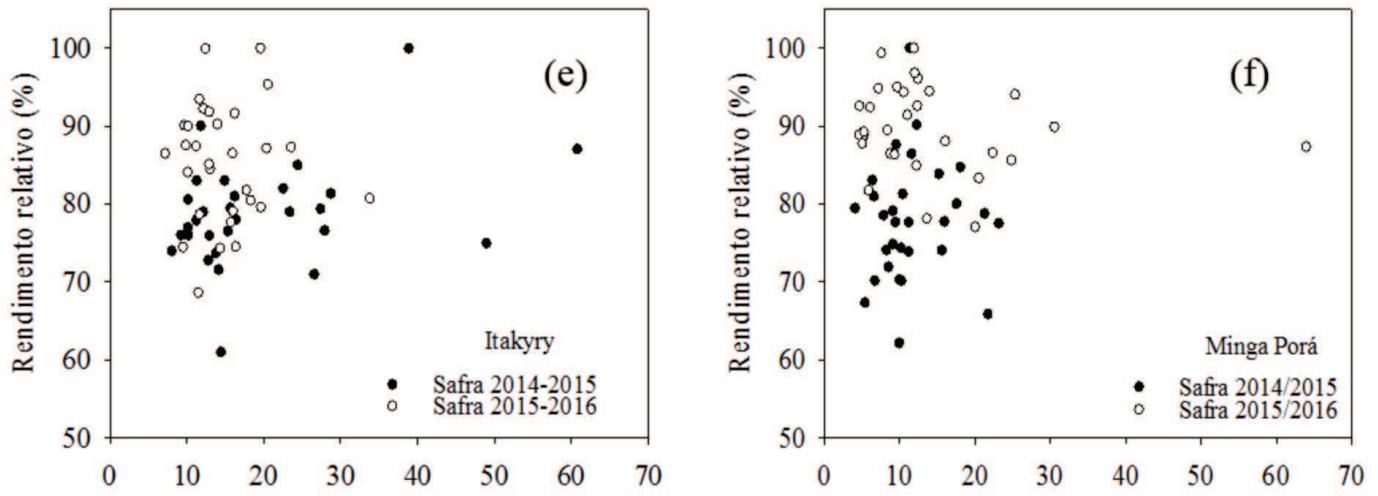

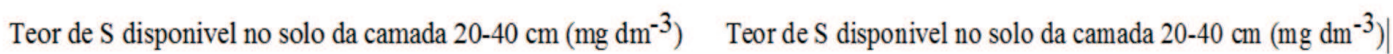

Linha pontilhada vertical indica o nível crítico de $10 \mathrm{mg} \mathrm{kg}{ }^{1}$ de $\mathrm{S}$ na camada $010 \mathrm{~cm}$, linha pontilhada horizontal indica o rendimento relativo de $85 \%$.

Figura 2: Relação entre teor de enxofre (S) disponível no solo nas camadas de $010 \mathrm{~cm} 1020 \mathrm{~cm}$ e $2040 \mathrm{~cm}$ e o rendimento relativo da soja nos anos agrícolas 2014/2015 e 2015/2016, nos locais de Itakyry (a, c, e) e Minga Porá (b, d, f). 
radicular pode condicionar às plantas melhor capacidade de absorção de água de camadas subsuperficiais, diminuindo o efeito negativo de períodos de stress por falta de água, que não foram observados durante o presente estudo.

Houve diferença entre os locais estudados para todas as variáveis analisadas, exceto o número de grãos por vagens (Tabela 2). O número de vagens por planta e número de grãos por planta foram superiores em Itakyry, o que resultou em uma maior produtividade de grãos, de 4,11 tha ${ }^{1}$, cerca de 0,45 t ha ${ }^{1}$ superior à encontrada em Minga Porá. As altas precipitações ocorridas em Itakyry num solo com textura arenosa (790 $\mathrm{g} \mathrm{kg}^{1}$ de areia) que apresenta maior macroporosidade, boa drenagem, boa aeração e maior resistência à compactação (Reichert et al., 2009) promoveram uma maior população de plantas sob superfície, provavelmente favoreceram os componentes de rendimento da soja. A altura de planta e massa de mil grãos foram
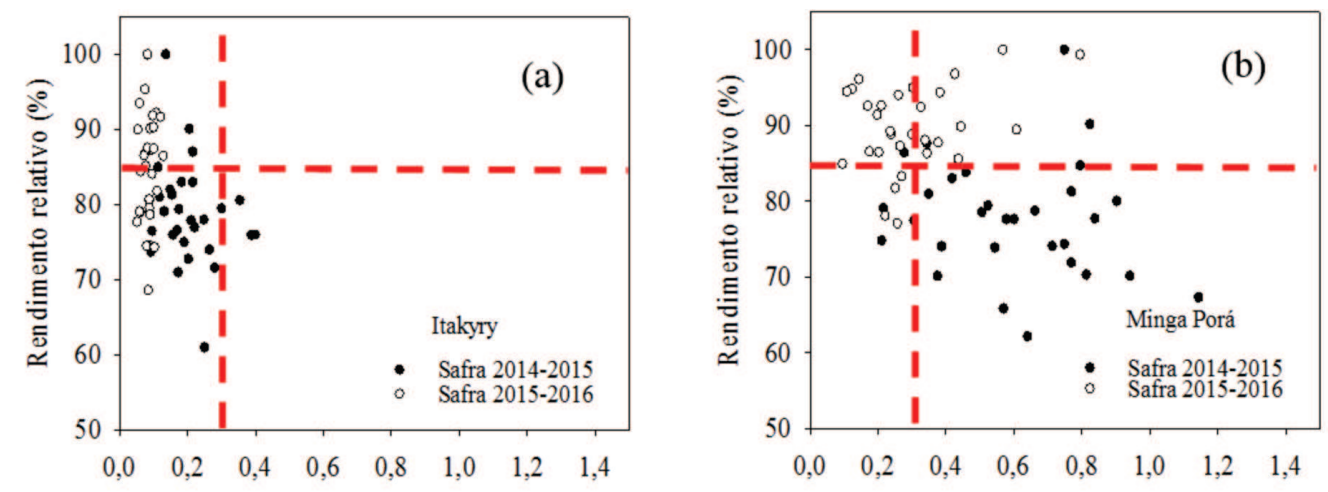

Teor de $\mathrm{K}$ disponível no solo da camada $0-10 \mathrm{~cm}\left(\mathrm{cmol}_{\mathrm{c}} \mathrm{dm}^{-3}\right)$

Teor de $\mathrm{K}$ disponível no solo da camada $0-10 \mathrm{~cm}\left(\mathrm{cmol}_{\mathrm{c}} \mathrm{dm}^{-3}\right)$
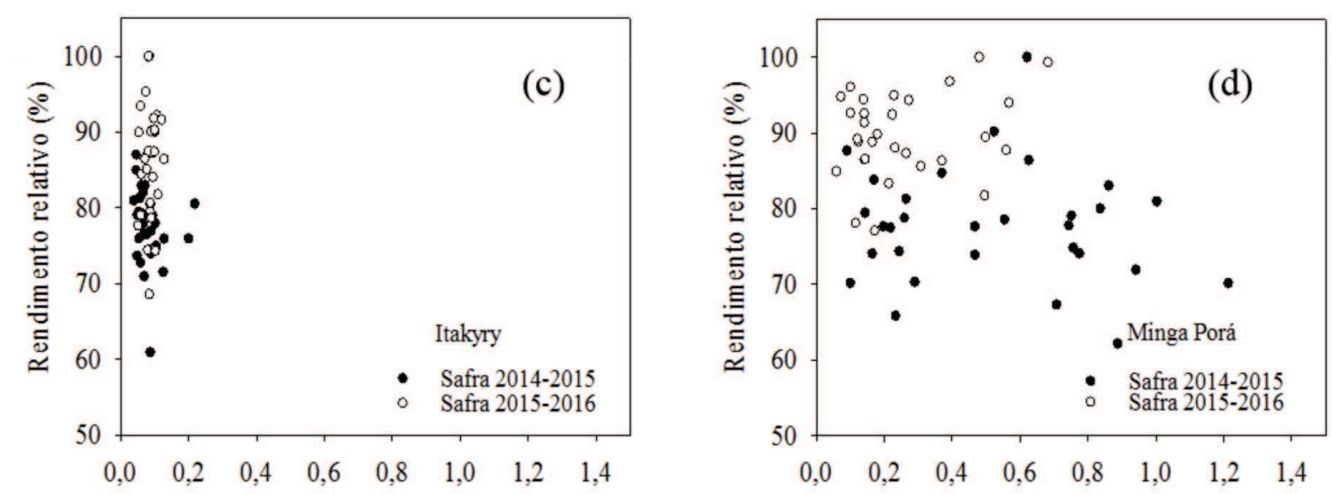

Teor de $\mathrm{K}$ disponivel no solo da camada $10-20 \mathrm{~cm}\left(\mathrm{cmol}_{\mathrm{C}} \mathrm{dm}^{-3}\right)$ Teor de $\mathrm{K}$ disponível no solo da camada $10-20 \mathrm{~cm}^{-}\left(\mathrm{cmol}_{\mathrm{C}} \mathrm{dm}^{-3}\right)$
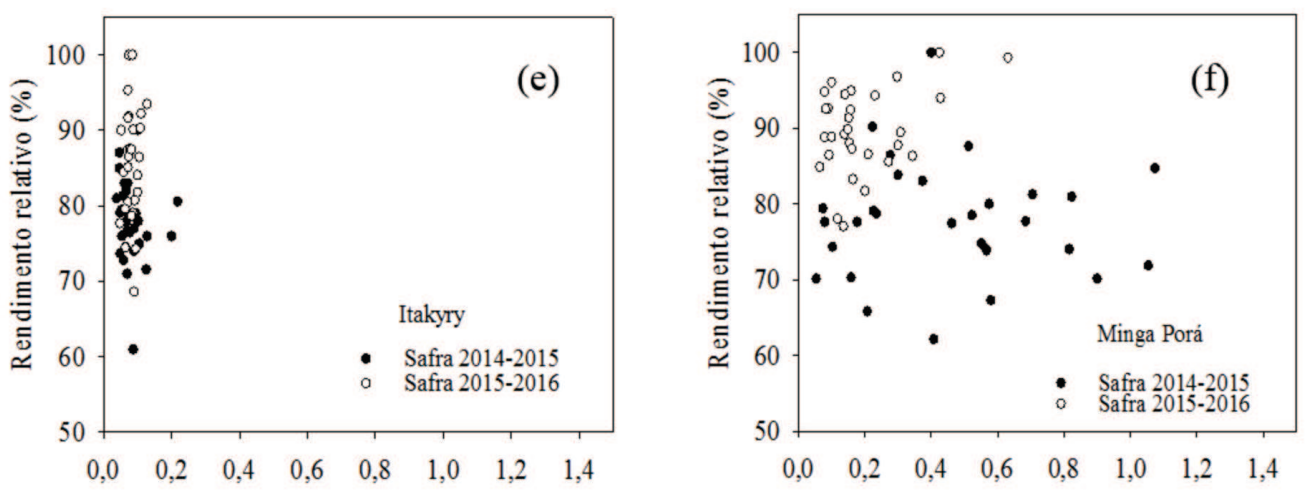

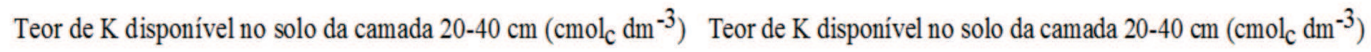

Linha pontilhada vertical indica o nível crítico de $0,15 \mathrm{cmol}_{\mathrm{c}} \mathrm{dm}^{3} \mathrm{de} \mathrm{K}$ na camada $010 \mathrm{~cm}$, linha pontilhada horizontal indica o rendimento relativo de $85 \%$.

Figura 3: Relação entre teor de teor de potássio (K) disponível no solo nas camadas de $010 \mathrm{~cm} 1020 \mathrm{~cm}$ e $2040 \mathrm{~cm}$ e o rendimento relativo da soja nos anos agrícolas 2014/2015 e 2015/2016, nos locais de Itakyry (a, c, e) e Minga Porá (b, d, f). 
maiores em Minga Porá, sem influenciar a produção de grãos entre locais.

A produtividade da soja também foi diferente nos anos agrícolas avaliados (Tabela 2). A média da produtividade de grãos entre locais e tratamentos foi de $4,12 \mathrm{t}$ ha ${ }^{1}$ na safra $2015 / 2016$, superior à ocorrida na safra 2014/2015 de 3,67 t ha ${ }^{1}$, já como consequência da alteração dos atributos químicos, aumentando a fertilidade química do solo.

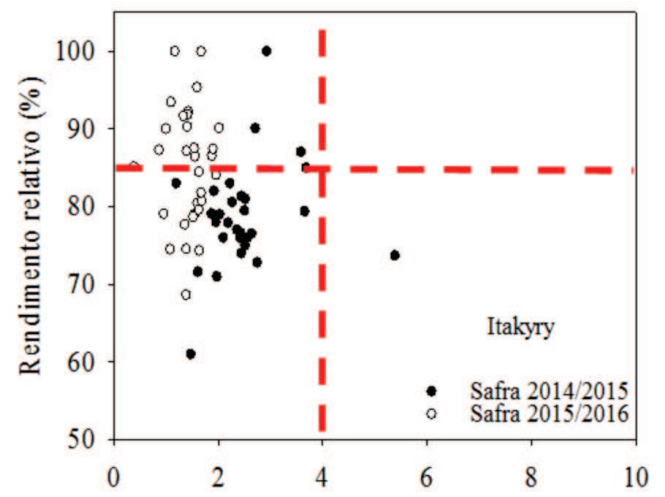

Teor de Ca disponível no solo da camada $0-10 \mathrm{~cm}\left(\mathrm{cmol}_{\mathrm{C}} \mathrm{dm}^{-3}\right)$

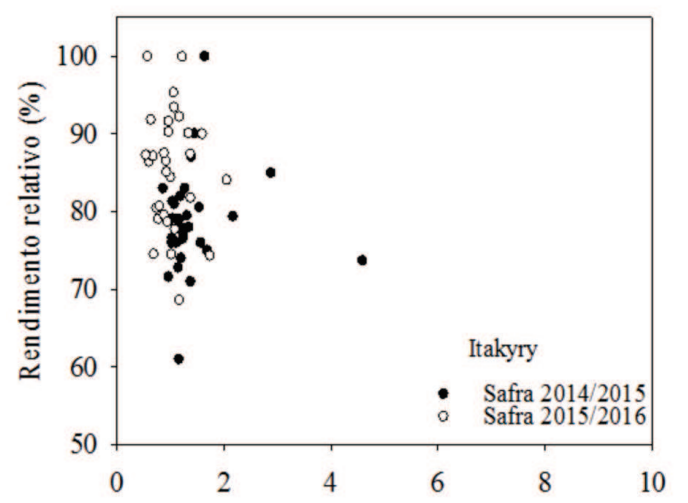

Teor de Ca disponível no solo da camada $10-20 \mathrm{~cm}\left(\mathrm{cmol}_{\mathrm{c}} \mathrm{dm}^{-3}\right)$

\section{Teores de nutrientes no tecido foliar e grão}

Os teores dos nutrientes $\mathrm{Ca}, \mathrm{Mg}, \mathrm{S}, \mathrm{P}$ e K nas folhas de soja no florescimento na safra 2015/2016 não foram influenciados pelas doses de gesso aplicadas (Tabela 3). A ausência de efeito pode estar relacionada aos altos conteúdos desses nutrientes no solo, mesmo no tratamento testemunha (Tabela 1), mantendo-se sempre em níveis considerados suficientes para a cultura (CQFS-SC/RS, 2016). Esses resultados estão de acordo

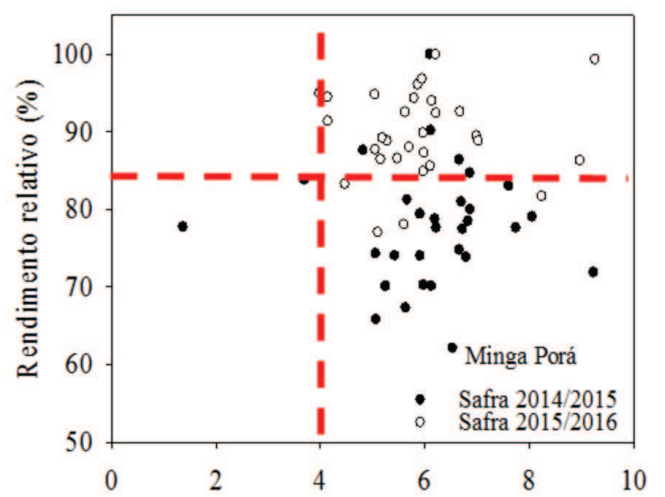

Teor de Ca disponível no solo da camada $0-10 \mathrm{~cm}\left(\mathrm{cmol}_{\mathrm{c}} \mathrm{dm}^{-3}\right)$

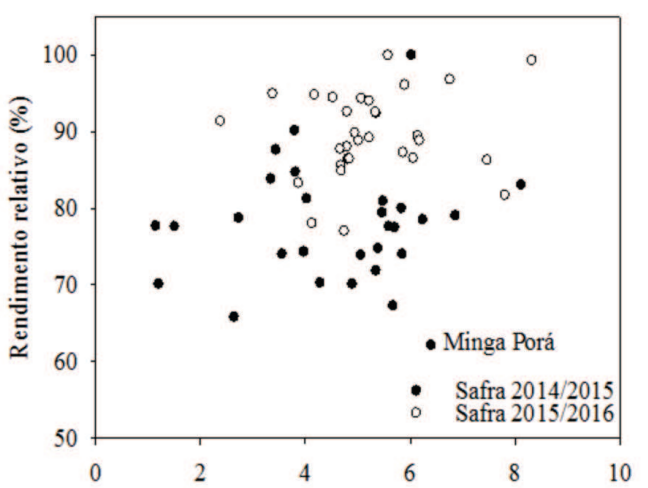

Teor de Ca disponivel no solo da camada $10-20 \mathrm{~cm}\left(\mathrm{cmol}_{\mathrm{C}} \mathrm{dm}^{-3}\right)$
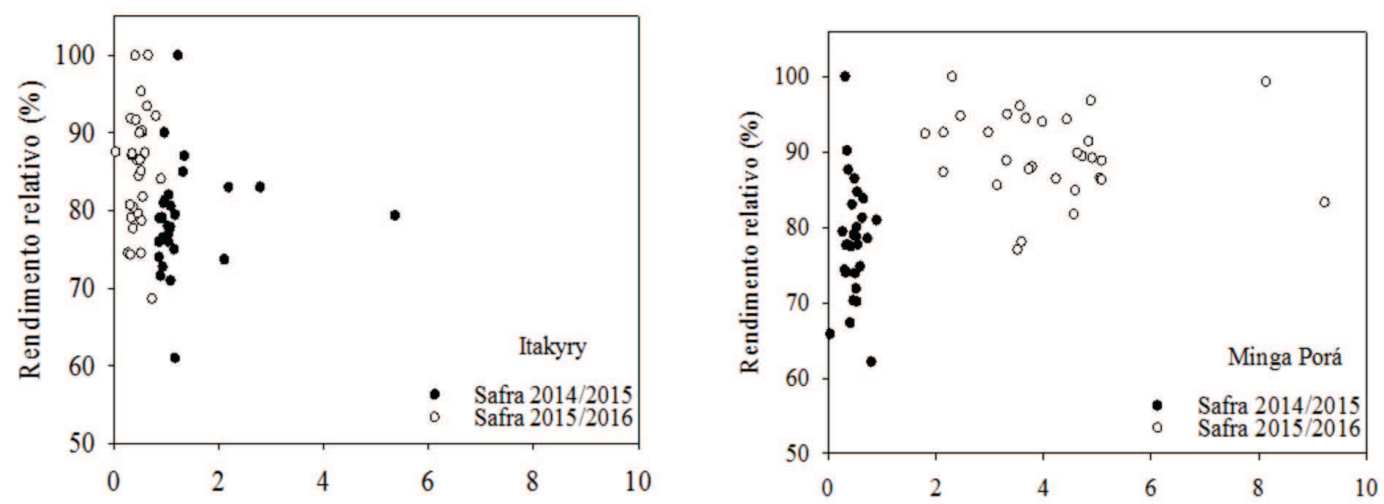

Teor de Ca disponivel no solo da camada $20-40 \mathrm{~cm}\left(\mathrm{cmolc} \mathrm{dm}^{-3}\right)$

Teor de Ca disponivel no solo na camada $20-40 \mathrm{~cm}\left(\mathrm{cmolc} \mathrm{dm}^{-3}\right)$

Linha pontilhada vertical indica o nível crítico de $4,0 \mathrm{cmol}_{\mathrm{c}} \mathrm{dm}^{3} \mathrm{de}$ Ca na camada $010 \mathrm{~cm}$; e linha pontilhada horizontal indica o rendimento relativo de $85 \%$.

Figura 4: Relação entre teor de cálcio (Ca) disponível no solo das camadas de $010 \mathrm{~cm} 1020 \mathrm{~cm}$ e $2040 \mathrm{~cm}$ e o rendimento relativo da soja nos anos agrícolas 2014/2015 e 2015/2016, nos locais de Itakyry (a, c, e) e Minga Porá (b, d, f). 
com Savio et al. (2011) e Pauletti et al. (2014), que não observaram alterações significativas na concentração de $\mathrm{Ca}, \mathrm{Mg}, \mathrm{S}, \mathrm{P}, \mathrm{K}$ e $\mathrm{Mg}$ no tecido foliar da soja com o uso de gesso. Em ambos os locais e anos agrícolas avaliados não houve efeito dos teores de $\mathrm{Ca}, \mathrm{Mg}, \mathrm{S}, \mathrm{P}$ e K nos grãos de soja em função das doses de gesso aplicadas em superfície. As interações entre doses, local e ano também não foram significativas. As médias de con- centração desses nutrientes estavam dentro da faixa considerada normal para a cultura (CQFS-SC/RS 2016) (Tabela 4).

A concentração de S no grão, independentemente da dose de gesso, variou entre 2,73 e $2,94 \mathrm{~g} \mathrm{~kg}^{1}$, considerados adequados para obter-se $90 \%$ de rendimento relativo máximo (Hitsuda et al., 2004). A condição climática favorável para a cultura ocorrida durante o experi-
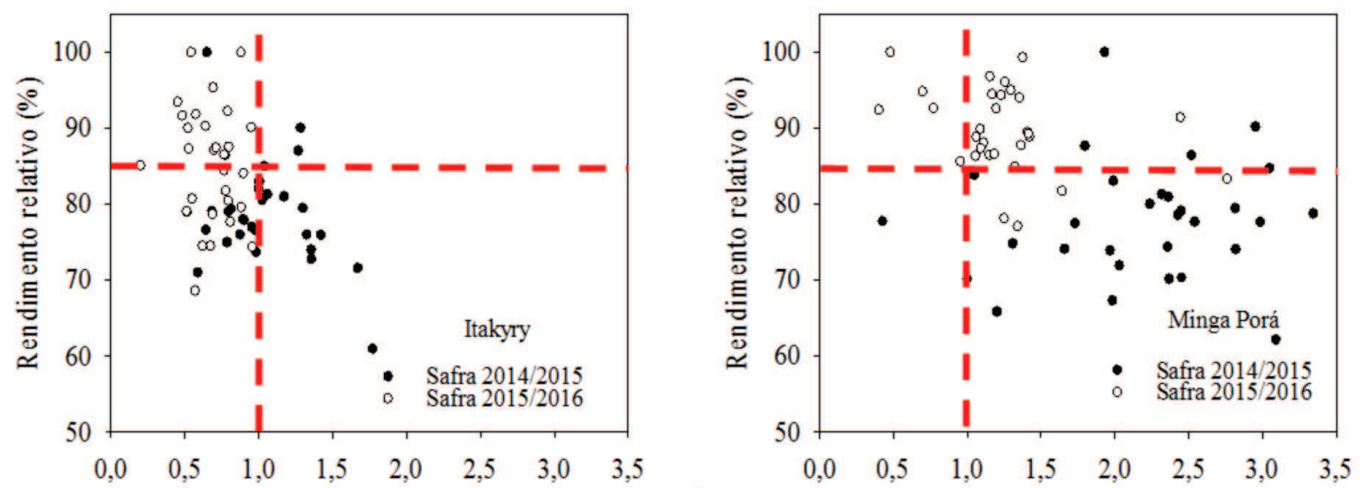

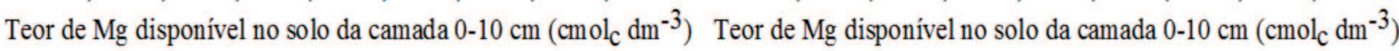
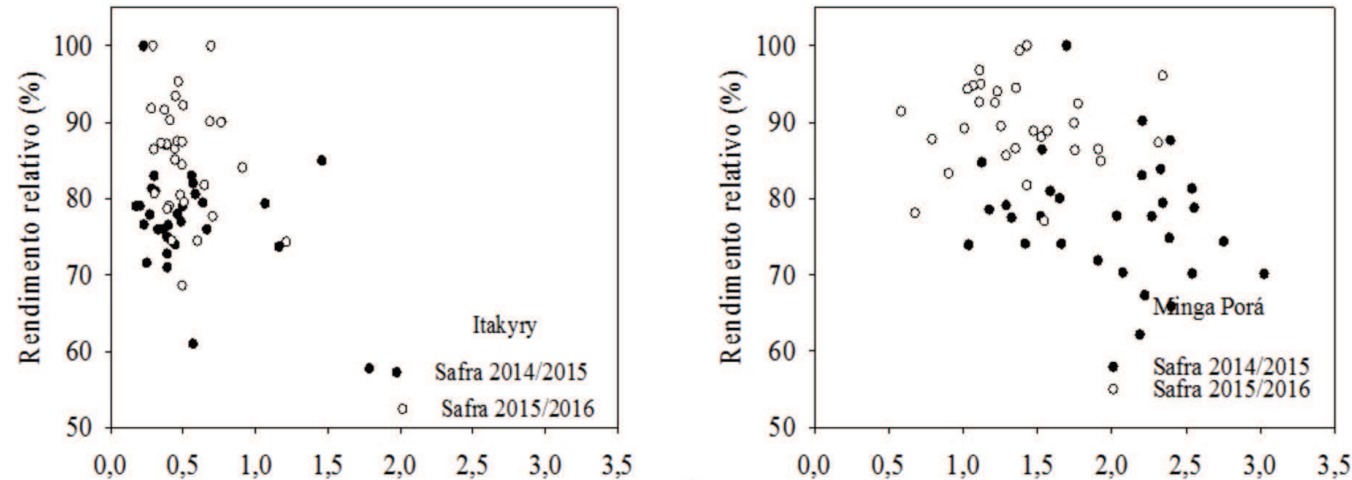

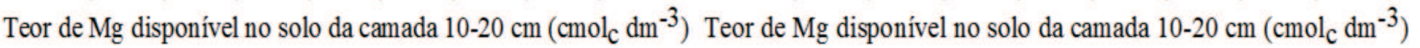
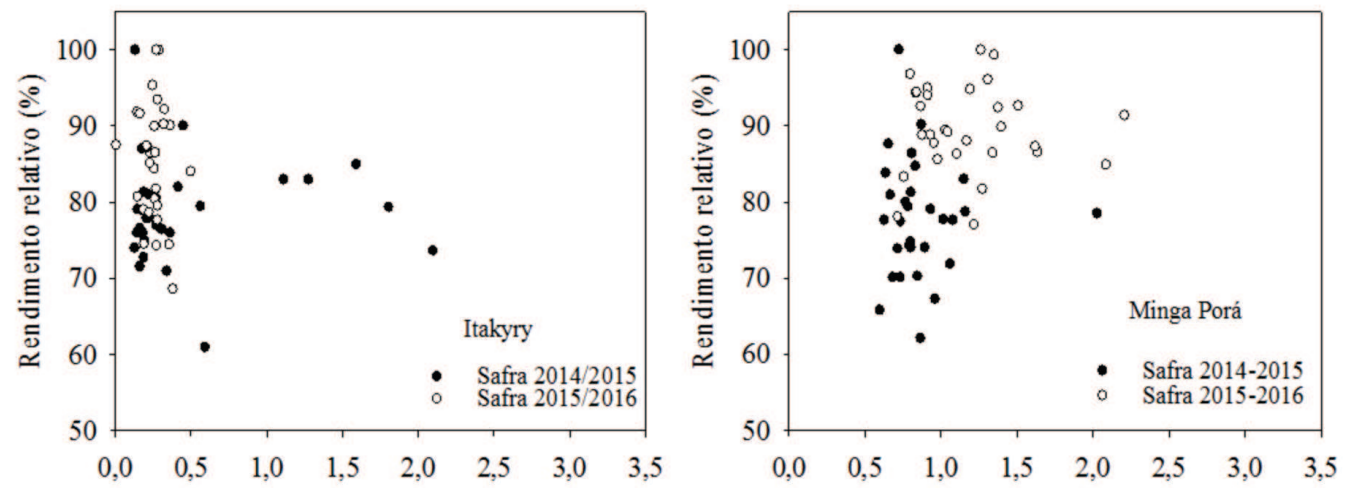

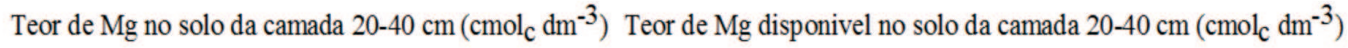

Linha pontilhada vertical indica o nível crítico de $1,0 \mathrm{cmol}_{\mathrm{c}} \mathrm{dm}^{3} \mathrm{de} \mathrm{Mg}$ de na camada $010 \mathrm{~cm}$; e linha pontilhada horizontal indica o rendimento relativo de $85 \%$.

Figura 5: Relação entre teor de magnésio (Mg) disponível no solo das camadas de $010 \mathrm{~cm} 1020 \mathrm{~cm}$ e $2040 \mathrm{~cm}$ e o rendimento relativo da soja nos anos agrícolas 2014/2015 e 2015/2016, nos locais de Itakyry (a, b, c, g, h, i) e Minga Porá (d, e, f, j, k, l). 
mento, e alta disponibilidade de nutrientes no solo, facilitou o acúmulo de nutrientes no grão, diminuindo a probabilidade de resposta à gessagem. A concentração de K no grão da cultura de soja foi maior em Minga Porá (18,0 $\left.\mathrm{g} \mathrm{kg}^{1}\right)$ do que em Itakyry (16,5 $\mathrm{g} \mathrm{kg}^{1}$ ) (Tabela 4), possivelmente devido ao maior teor de $\mathrm{K}$ no solo nesse local $\left(0,70 \mathrm{cmol}_{\mathrm{c}} \mathrm{kg}^{1}\right)$ que favoreceu maior acúmulo do nutriente no grão.

\section{Relação da produtividade com parâmetros químicos do solo}

Não houve relação entre o teor de $\mathrm{S}$ disponível no solo nas camadas 010,1020 e $2040 \mathrm{~cm}$ com rendimento relativo da soja nos cultivos avaliados (Figura 2). Isso demonstra que a produtividade da soja não foi limitada pelos teores de $\mathrm{S}$, mesmo quando o solo apresentou teores de $\mathrm{S}$ disponível menores que $10 \mathrm{mg} \mathrm{kg}^{1}$ nas três cama-
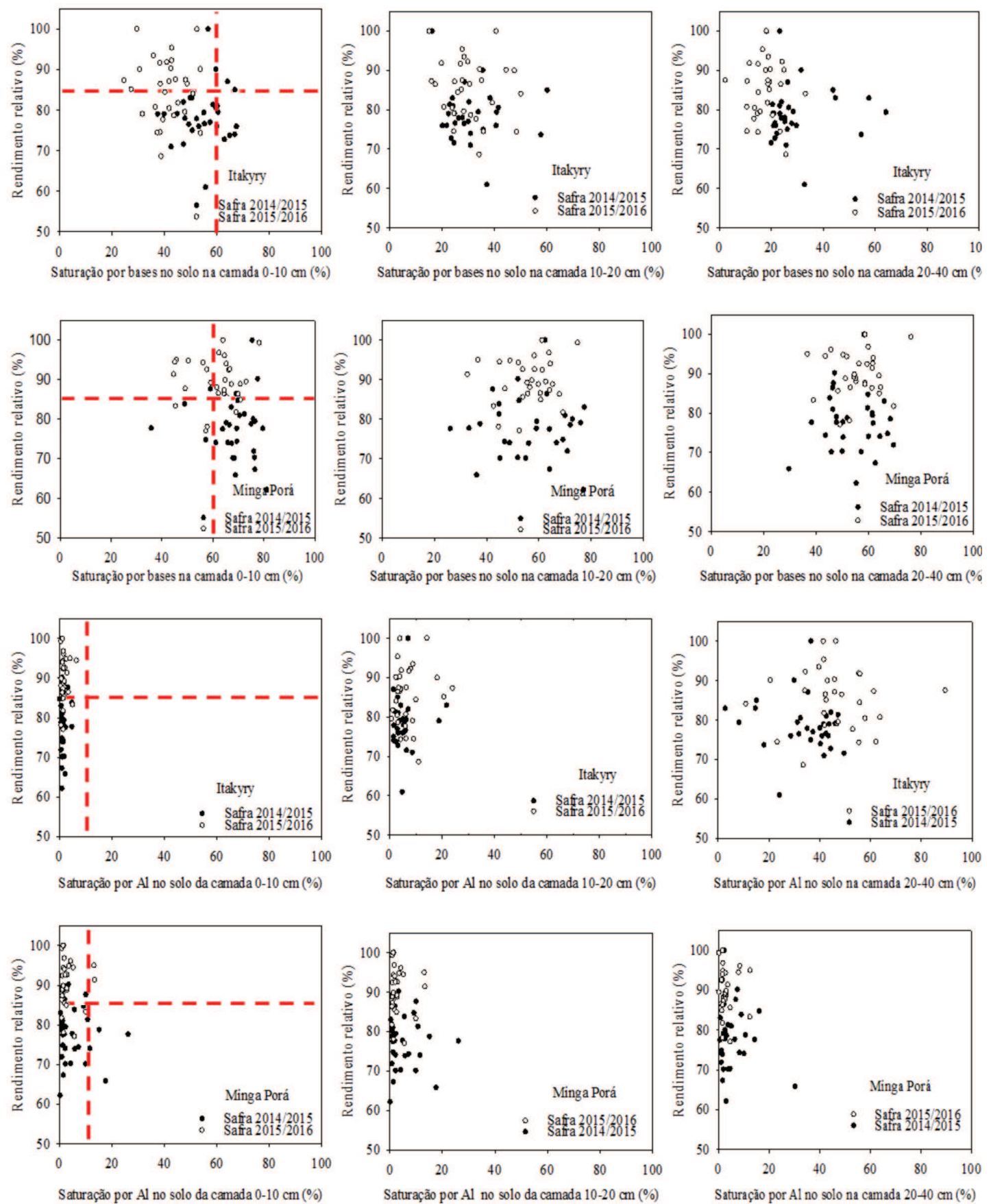

Linha pontilhada vertical indica o nível crítico de $60 \%$ de saturação por bases e $10 \%$ de saturação por Al na camada 010 cm; e linha pontilhada horizontal indica o rendimento relativo de $85 \%$.

Figura 6: Relação entre saturação por bases (V) e saturação por Al (m) nas camadas de $010 \mathrm{~cm} 1020 \mathrm{~cm}$ e $2040 \mathrm{~cm}$ e o rendimento relativo da soja nos anos agrícolas 2014/2015 e 2015/2016, nos locais de Itakyry (a, b, c, g, h, i) e Minga Porá (d, e, f, j, k, l). 
das. A falta de correlação pode estar relacionada ao fato de que o teor de $\mathrm{S}$ não era limitante para a cultura em ambos locais. A MO é um importante reservatório de nutrientes como o S no solo, e o teor de MO no solo foi de $15 \mathrm{~g} \mathrm{~kg}^{1}$ em Itakyry e $42 \mathrm{~g} \mathrm{~kg}^{1}$ em Minga Porá (Tabela 1). A disponibilidade de K (Figura 3) nas camadas $010 \mathrm{~cm} 10$ $20 \mathrm{~cm}$ e $2040 \mathrm{~cm}$ em Itakyry (Argissolo) foram inferiores ao teor crítico de $0,15 \mathrm{cmol}_{\mathrm{c}} \mathrm{dm}^{3}$, e em Minga Porá (Latossolo) observou-se o contrário, teores de K superiores a $0,15 \mathrm{cmol}_{c} \mathrm{dm}^{3}$, ambos sem mostrar relação com o rendimento relativo da cultura de soja.

Os teores de Ca e Mg (Figura 4,5) no solo não apresentaram relação com rendimento relativo da soja nas três profundidades avaliadas nos locais, mesmo quando os teores de Ca e $\mathrm{Mg}$ estiveram por abaixo de 4,0 e 1,0 $\mathrm{cmol}_{\mathrm{c}}$ $\mathrm{dm}^{3}$ respectivamente.

Não houve relação entre os teores da saturação por bases e saturação por Al (Figura 6) de acordo a CQFS/RSSC (2016) no solo com o rendimento relativo da soja em todas as safras avaliadas, mesmo quando o solo apresentou saturação por bases menor que $60 \%$ e saturação por Al maior que $10 \%$ das camadas 010,1020 e $2040 \mathrm{~cm}$. A saturação por $\mathrm{Al}$ foi mínima, próxima à zero nas três profundidades, relacionada à ausência de níveis prejudiciais do Al no solo (Tabela 1 ).

\section{CONCLUSÕES}

Os componentes de rendimento de grãos e a produtividade da soja não foram influenciados pela aplicação de doses de gesso de 0 a $1600 \mathrm{~kg} \mathrm{ha}{ }^{1}$ em um Argissolo e um Latossolo do Departamento do Alto Paraná, Paraguai com teores de $\mathrm{S}, \mathrm{MO}$ e $\mathrm{Al}$ de $10,4 \mathrm{e} 7,6 \mathrm{mg} \mathrm{dm}{ }^{-3}, 10$ e $35 \mathrm{~g} \mathrm{~kg}^{-1} \mathrm{e}$ 0,4 e $1,3 \mathrm{cmol}_{\mathrm{dm}^{-3}}$ na camada $1020 \mathrm{~cm}$ respectivamente. Os teores de $\mathrm{Ca}, \mathrm{Mg}, \mathrm{S}, \mathrm{P}$ e $\mathrm{K}$ na folha da soja não foram afetados pela aplicação das doses de gesso em Itakyry e Minga Porá nos anos agrícolas de 2014/2015 e 2015/2016. Os teores de $\mathrm{S}$, Ca e Mg disponível, saturação por bases e saturação por alumínio no solo das camadas 010,1020 e 2040 não se correlacionaram com o rendimento relativo da soja em todos os cultivos avaliados.

\section{REFERÊNCIAS}

Alcântara J, Cardoso GC \& Lambert RA (2014) Influência da aplicação de calcário e gesso na cultura da soja (Glycine max L. Merrill). Enciclopédia Biosfera, 18:1980-1988.

Bortoluzzi EC, Parize GL, Korchagin J, Rodrigues V, Rheinheimer D \& Kaminski J (2014) Soybean root growth and crop yield in reponse to liming at the beginnig of a no-tillage system. Revista Brasileira de Ciência do Solo, 38:262-271.

Caires EF, Joris HAW \& Churka S (2011a) Long-term effects of lime and gypsum additions on no-till corn and soybean yield and soil chemical properties in southern Brazil. Soil Use Manage, $27: 45-53$.
Caires E, Garbuio F, Churka S \& Joris H (2011b) Use of gypsum for crop grain production under a subtropical no-till cropping system. Agronomy Journal, 103:1804-1814.

Cate RB \& Nelson LA (1971) A simple statical procedure for partitioning soil test correlation data into two clases. Soil Sciencie Society of America Journal, 5:658-660.

CQFS - Comissão de Química e Fertilidade do Solo RS/SC (2016) Manual de adubação e calagem para os Estados do Rio Grande do Sul e Santa Catarina. Porto Alegre, SBCS- Núcleo Regional Sul. $376 \mathrm{p}$.

Crusciol CA, Nascente A, Mateus GP \& Borghi LE (2014) Intercropping soybean and palisade grass for enhanced land use efficiency and revenue in a no till system. European Journal of Agronomy, 58:53-62.

Di Renzo JA, Casanoves F, Balzarini MG \& Gonzalez L (2011) INFOSTAT: Software Estadístico. Versão 2011. Córdoba, Universidad Nacional de Córdoba. CD- ROM.

Embrapa Empresa Brasileira de Pesquisa Agropecuária (2013) Sistema brasileiro de classificação de solos. Centro Nacional de Pesquisa de Solos. $3^{a}$ ed. Brasília, Embrapa. 353p.

Embrapa Empresa Brasileira de Pesquisa Agropecuária (2003) Recomendações técnicas para Mato Grosso do Sul e Mato Grosso. Dourados, Centro de Pesquisa Agropecuária do Oeste. 60p.

Ferreira NR, Alvarez VH, Barros FN de, Fontes RL, Cantarutti RB \& Lima NJC (2007) Fertilidade do solo. Viçosa, Sociedade Brasileira de Ciência do Solo. 1017p.

Fontoura SM, Bayer C, Vieira RC \& Moraes RP (2012) Calcário e gesso. Efeito na produtividade de culturas e na melhoria química do solo em plantio direto no Centro-Sul do Paraná. Guarapuava, Fundação Agrária de Pesquisa Agropecuária. 34p.

Gentiletti A \& Gutiérrez FH (2004) Fertilización azufrada del cultivo de soja en el Centro-Sur de Santa Fe. Informaciones agronómicas, 24:01-09.

Hahn E \& Fioretto C (2017) Fertilidad de los suelos de la Región Oriental. In: Hanh E (Ed.) Diagnóstico de la Fertilidad de los suelos de la Agricultura Familiar paraguaya: Región Oriental. Asunción, Atlas. p.177-191.

Hitsuda K, Sfredo G \& Klepker D (2004) Diagnosis of sulfur deficiency in soybean using seeds. Soil Science Journal, 68:14451451.

Lana MC, Fey R, Frandoloso JF, Richart A \& Fontaniva S (2016) Análise química de solo e tecido vegetal: práticas de laboratório. $2^{\mathrm{a}}$ ed. Marechal Cándido Rondón, Universidade Estadual do Oeste de Paraná. 153p.

López GO, González E, De Llamas P, Molinas A, Franco S, García S \& Ríos E (1995) Estudio de Reconocimiento de suelos, capacidad de uso de la tierra y propuesta de ordenamiento territorial preliminar de la Región Oriental del Paraguay. Proyecto de Racionalización del uso de la tierra. Asunción, SSERNMA/MAG/Banco Mundial. 51p.

Moda LR, Borges BM, Flores RA, Dos Santos CL, Prado RM \& Sousa JI (2013) Gessagem na cultura da soja no sistema de plantio direto com e sem adubação potássica. Revista Agro@mbiente, 7:129-135.

Neis L, Paulino HB, De Souza EM, Dos Reis OF \& Pinto FA (2010) Gesso agrícola e rendimento de grãos de soja na região do sudoeste de Goiás. Revista Brasileira de Ciência do Solo, 34:409-416.

Pauletti V, Pierri LD, Ranzan T, Barth G \& Motta AC (2014) Long-term effects of the application of gypsum and lime in a no-till system. Revista Brasileira de Ciência de Solo, 38:495505 . 
Pimentel Gomes F (2002) Estadística aplicada a experimentos agronômicos e florestais: exposição com exemplos e orientações para uso de aplicativos. Piracicaba, FEALQ. 309p.

Rampim L, Lana MC, Frandoloso JF \& Fontaniva S (2011) Atributos químicos de solo e resposta do trigo e da soja ao gesso em sistema semeadura direta. Revista Brasileira de Ciência de Solo, $35: 687-1698$

Reichert JM, Suzuki LE, Reinert DJ, Horn R \& Håkansson I (2009) Reference bulk density and critical degree-of compactness for no-till crop production in subtropical highly weathered soils. Soil \& Tillage Research, 102:242-254.

Saldanha EC, César E, Tavares Da Rocha A, Almeida De Oliveira E, Nascimento WC \& Freire FJ (2007) Uso do gesso mineral em Latossolo cultivado com cana de açúcar. Revista Caatinga, 20:3642.

Sávio FL, Silva GC, Teixeira IR, Mota JH \& Borém A (2011) Calagem e gessagem na nutrição e produção de soja em solo com pastagem degradada. Revista Agrotecnologia, 2:19-31.

SBCS Sociedade Brasileira de Ciência de Solo (2017) Manual de adubação e calagem para o estado do Paraná. Curitiba, SBCS/ NEPAR. 482p.
USDA (1993) Examination and description of soils. In: Soil Survel Manual. Soil Science Division Staff. Washington, USDA. p.46155 .

Sousa DM, de Lobato E \& Rein TA (2005) Uso do gesso em solos do Cerrado. Planaltina, Embrapa Cerrados. 20p. (Circular técnica, 32).

Soratto RP, Crusciol CA \& Mello F (2010) Componentes da produção e produtividade de cultivares de arroz e feijão de calcário e gesso aplicados na superfície do solo. Bragantia, 69:965-974.

Tiecher T, Rheinheimer DS, Rasche JW, Brunetto G, Mallman FJ \& Piccin R (2012) Resposta de culturas e disponibilidade de enxofre em solos com diferentes teores de argila e matéria orgânica submetida à adubação sulfatada. Bragantia, 20:01-10.

Tiecher T, Rheinheimer D, Rasche JW, Mallmann FJ, Piccin R \& Brunetto G (2013) Respostas de culturas à adubação sulfatada e deposição de enxofre atmosférico. Revista Ceres, 60:420-427.

Zandoná RR, Beutler NA, Burg GM, Barreto CF \& Schmidt MR (2015) Gesso e calcário aumentam a produtividade e amenizam o efeito do déficit hídrico em milho e soja. Pesquisa Agropecuária Tropical, 45:128-137. 